\title{
TDAH e Ritalina: neuronarrativas em uma comunidade virtual da Rede Social Facebook
}

\author{
ADHD and Ritalin: neuronarratives \\ in a virtual community of Facebook Social Network
}

Fernanda Martinhago ${ }^{1}$

${ }^{1}$ Programa de PósGraduação Interdisciplinar em Ciências Humanas, Universidade Federal de Santa Catarina. R. Eng. Agronômico Andrei Cristian Ferreira s/n, Trindade. 88040-900 Florianópolis SC Brasil. martinhagofernanda@ gmail.com

\begin{abstract}
Attention Deficit Hyperactivity Disor$\operatorname{der}(A D H D)$ is notable for affecting between 5\% and $10 \%$ of the child and adolescent populations in several continents. The main treatment for this is methylphenidate (Ritalin). In this context, the objective of this research was to understand how the contents transmitted in social networks (virtual communities) influence the way family members of these communities understand $A D H D$ and its treatment, as well as how they deal with their children who are suspected of having, or are already diagnosed with, $A D H D$. The research was developed from the standpoint of Medical Anthropology. Virtual ethnography was chosen as the research methodology to observe a virtual community from the social network Facebook. The virtual community investigated consisted mainly of mothers of children and adolescents diagnosed with $A D H D$, and it was observed that they mainly discuss the use of medication (Ritalin or Concerta) to treat ADHD in their children. The narratives show that it causes a lot of anxiety in some mothers to give their children controlled substances. We live in an age in which the vissicitudes of life have been pathologised. As a result, parental suffering, as caused by the difficulties of dealing with their children, leads to the idea that medical solutions are necessary for them to aleviate their children's conditions
\end{abstract}

Key words $A D H D$, Ritalin, Social network
Resumo O Trantorno de Déficit de Atenção e Hiperatividade (TDAH) destaca-se por atingir cerca de 5\% a 10\% da população infanto-juvenil em diversos continentes, sendo a principal opção de tratamento o uso do metilfenidato (Ritalina). Neste contexto, esta pesquisa teve como objetivo compreender como os conteúdos veiculados nas redes sociais (comunidades virtuais) influenciam no modo pelo qual os familiares, membros destas comunidades, entendem o TDAH e o tratamento, bem como lidam com seus filhos com suspeita ou já diagnosticados com TDAH. A pesquisa foi desenvolvida na perspectiva da Antropologia Médica. A etnografia virtual foi elegida como metodologia de investigação para adentrar a uma comunidade virtual da rede social Facebook. Observou-se que a comunidade virtual investigada, constituída por mães de crianças e adolescentes diagnosticados com TDAH, discute principalmente o uso da medicação para tratamento do TDAH em seus filhos. As narrativas indicam que causa muita angústia em algumas mães darem a seus filhos um medicamento controlado. O sofrimento dos pais mediante as dificuldades de lidarem com seus filhos induz a ideia de que há necessidade de uma solução médica, pois vivemos em uma era em que os percalços da vida tornaram-se patologias. Palavras-chave TDAH, Ritalina, Rede social 


\section{Introdução}

Nos últimos anos, os saberes biomédicos e neurocientíficos têm privilegiado uma ideia cerebralizada do self $f^{\mathrm{f}}$. Este processo tem tido êxito em função das novas neurotecnologias de representação e visualização cerebral, bem como pelo desenvolvimento de medicamentos para o tratamento do sofrimento psíquico e a presença dos discursos neuroculturais na cultura pública e nos meios de comunicação de massa ou social (mass media). Martínez-Hernáez ${ }^{1}$ denomina esses discursos de neuronarrativas, que são relatos que privilegiam explicações em que o sofrimento ocorre em função de disfunções cerebrais, encobrindo as dimensões sociais que permeiam as aflições.

Estamos vivendo em tempos demarcados pela cerebralidade, em que os neologismos emergem no cerne da linguagem convencional (neuroestética, neuroética, neurodesenvolvimento, neuroeducação, neurodidática, etc), bem como novas formas de biossocialidades ou neurossociabilidades que se constituem no imaginário e se tornam reais no simbólico ${ }^{1}$. Assim, pode-se dizer que estamos em "épocas de neuro" e, dentre os avanços e retrocessos que vivenciamos em função destas transformações, emerge uma grande preocupação pertinente ao campo da saúde mental, uma epidemia de transtornos mentais.

Tal epidemia é chamada por Whitaker ${ }^{2}$ de "praga moderna", uma vez que nunca houve uma prevalência tão alta de pessoas diagnosticadas com transtornos mentais como na contemporaneidade. Conforme nota o autor, a história contada para a sociedade é a de que a psiquiatria havia progredido no tratamento dos transtornos mentais, os pesquisadores estariam descobrindo as causas biológicas destes transtornos e a indústria farmacêutica havia desenvolvido medicamentos eficazes para o tratamento. Porém, ao fazer uma análise da incidência de transtornos mentais dos últimos 50 anos, Whitaker ${ }^{2}$ constatou que há uma verdadeira epidemia de transtornos mentais. Por exemplo, nos Estados Unidos, em 1955, uma em cada 468 pessoas sofria de algum transtorno mental. Em 1987, uma a cada 184 pessoas estava diagnosticada com um transtorno mental. Em 2007, o número passou a ser de um diagnosticado para cada 76 estadunidenses.

A "praga de transtornos mentais" expandiuse a ponto de crianças e adolescentes também começarem a fazer parte destas estatísticas, as quais apontam um número elevado de transtornos mentais nesse público. No início da era psicofar- macológica, poucas eram as crianças diagnosticadas com transtornos mentais. As crianças eram consideradas travessas, inquietas, dispersas, mas não recebiam o diagnóstico de Transtorno de Déficit de Atenção e Hiperatividade (TDAH). Já os adolescentes eram considerados tímidos, emocionalmente inconstantes, todavia a sociedade esperava que na idade adulta seriam pessoas aptas para assumir suas responsabilidades, ter uma profissão, enfim, serem sujeitos normais. O olhar sobre a infância começou a ser revisto a partir do momento em que a psiquiatria passou a tratar crianças e adolescentes com medicamentos psicotrópicos. A justificativa apresentada pela psiquiatria é a da descoberta, nos últimos 50 anos, que crianças e adolescentes sofriam de patologias mentais de origem biológica. E assim surgiram o TDAH, a depressão, o transtorno bipolar, entre outras patologias no público infanto-juvenil ${ }^{2}$.

$\mathrm{O}$ aumento significativo de diagnósticos de transtornos mentais no público infanto-juvenil é atribuído às últimas versões do Manual Diagnóstico e Estatístico de Transtornos Mentais (DSM). No DSM-IV, conforme reconheceu Allen Frances $^{3}$ - chefe da força tarefa de execução do Manual -, houve imprevistos na elaboração que desencadearam falsas epidemias de transtornos mentais infantis, como: autismo, déficit de atenção e transtorno bipolar infantil. Para Frances ${ }^{3}$, o método de elaboração do DSM-IV deveria ter enfatizado a moderação, com objetivo de resguardar o Manual da individualidade, da arbitrariedade e da criatividade diagnóstica.

No caso do TDAH, o diagnóstico é clínico, pois não existem exames laboratoriais que possam comprovar tal patologia. Desse modo, qualquer pessoa pode facilmente receber o diagnóstico deste transtorno mental e uma prescrição para tratamento medicamentoso ${ }^{3}$. Esta vulnerabilidade do diagnóstico facilita que um número significativo de pessoas receba um diagnóstico falso -positivo e que isso possa ocorrer pela influência do marketing, pois o TDAH atinge cerca de 5\% a $10 \%$ da população infanto-juvenil em diversos continentes $^{3-6}$.

Entre as décadas de 1980 e início dos anos 1990, o TDAH era um fenômeno que ocorria majoritariamente nos Estados Unidos. Mediante este sucesso, a Associação Americana de Psiquiatria (APA), em parceria com as companhias farmacêuticas, começou a expandir o diagnóstico por outros países, como na Alemanha, onde os diagnósticos aumentaram $381 \%$ dos anos de 1989 a 2001; no Reino Unido, onde as prescrições de medicamentos para o TDAH aumenta- 
ram 50\% entre 2007 e 2012; em Israel, onde as prescrições duplicaram entre os anos de 2005 a 2012. Em países fora dos Estados Unidos, o uso mundial de Ritalina em 2007 era de 17\%, passando para 34\% em 2012. Nos Estados Unidos, nesse mesmo ano, $10 \%$ de crianças e adolescentes, com idades entre 4 e 18 anos, foram diagnosticadas com TDAH. As vendas globais de medicamentos para o TDAH renderam 11,5 bilhões de dólares em $2013^{6}$.

Apesar de obter destaque nos Estados Unidos na década de 1980, antes disso Conrad e Schneider $^{7}$ nos revelam que o TDAH foi chamado de hipercinesia, conhecida também anteriormente como disfunção cerebral mínima, síndrome hiperativa, desordem hipercinética da infância. Estas patologias apresentavam uma prevalência de diagnósticos médicos em torno de $3 \%$ a $10 \%$ na população escolar, percentuais semelhantes aos atuais do TDAH. Os sintomas variam pouco de categoria para categoria, sendo o diagnóstico baseado em comportamentos como hiperatividade (excesso extremo de atividade motora); atenção breve (a criança pula de atividade em atividade); agitação, inquietação, oscilação de humor (a criança está bem um dia e no outro não); apresenta um comportamento agressivo, impulsividade, incapacidade de se sentar na escola e cumprir as regras, baixa tolerância à frustração, problemas para dormir e atraso da aquisição da fala.

Durante os anos de 1970, a psiquiatria começou a prescrever metilfenidato (Ritalina) para as crianças hipercinéticas, pois já haviam constatado a mudançca de comportamento em sala de aula. Este fato reforçou a iniciativa da APA de criar um diagnóstico para os comportamentos correspondentes, que a princípio foi denominado no DSM-III (1980) de "Transtornos do Déficit de Atenção”. Este transtorno era caracterizado pelos sintomas de desatenção, impulsividade e hiperatividade, podendo, entretanto, ser diagnosticado sem a presença da hiperatividade. Em 1987, quando a APA publicou a versão revisada do DSM-III, os limites diagnósticos foram reconfigurados e o transtorno mencionado acima foi renomeado para "Transtorno do Déficit de Atenção com Hiperatividade”(TDAH). Em 1994, com a publicação da versão revisada do DSM-IV, seus limites diagnósticos foram ampliados novamente, definidos em três sub-tipos: somente desatento, somente hiperativo/impulsivo e aqueles que apresentam os dois sintomas ${ }^{7}$.

No DSM- $5^{4}$, última edição do manual de transtornos mentais, o TDAH e outros transtornos (Deficiências Intelectuais, Transtornos da
Comunicação, Transtorno do Espectro Autista, Transtorno Específico de Aprendizagem, Transtornos Motores) foram denominados como "Transtornos do Neurodesenvolvimento". Esta denominação diz respeito a transtornos que se manifestam durante o desenvolvimento da criança, geralmente antes da idade escolar. As principais características desses transtornos são os déficits de desenvolvimento que englobam limitações específicas na aprendizagem ou no controle de funções executivas, gerando prejuízos globais em habilidades sociais ou inteligência. Os critérios diagnósticos do TDAH incluem dois subtipos: 1) desatenção e/ou 2) hiperatividade e impulsividade. Para diagnosticar o transtorno são necessários seis sintomas relacionados a cada subtipo ou aos dois, por um período de seis meses para crianças e adolescentes até 16 anos, em um grau que seja inconsistente com o nível do desenvolvimento e que afete negativamente atividades sociais e escolares. Salienta-se que uma criança ou adolescente que apresenta sintomas somente relacionados a um dos dois subtipos é diagnosticada com TDAH.

Assim, o contexto escolar aparece como um lugar propício para identificar tais problemas relacionados ao comportamento, pelo fato de algumas crianças não seguirem as regras da escola, como ficarem sentadas, caladas e prestando atenção nas aulas por várias horas. O comportamento das crianças não corresponde às expectativas dos professores, os quais mencionam suas queixas aos pais que encaminham seus filhos para uma avaliação psiquiátrica já com indício de algum desvio ${ }^{8}$.

Uma pesquisa ${ }^{9}$ realizada na Catalunha com profissionais da educação e da saúde, pais e estudantes, buscou identificar a realidade dos problemas de comportamento nas escolas, com ênfase no Transtorno do Déficit de Atenção com ou sem Hiperatividade (TDA/H), bem como no Transtorno Negativista Desafiador e no Transtorno Dissocial. Os resultados da pesquisa demonstraram que os comportamentos de desordem estão associados com: a hiperatividade, o que faz com que as crianças não permaneçam quietas nos ambientes que exigem este comportamento; a impulsividade, as crianças agem sem considerar as consequências de suas ações; e o terceiro tipo de comportamento perturbador refere-se à violência que pode ser exercida sobre pessoas, animais ou objetos. Esses comportamentos foram considerados muito frequentes por $50 \%$ dos professores participantes da pesquisa. Neste sentido, a percepção dos profissionais da educação é que 
desempenham o seu trabalho em um ambiente de conflito. Dentre estes resultados, destacam-se dois vetores: um vetor de atenção e um outro vetor de conduta. O primeiro está relacionado com os problemas que surgem em consequência da falta de atenção no âmbito escolar. Por exemplo, quando se aponta que um estudante tem déficit de atenção, não está especificado em que atividades não se concentra. Um estudante que é capaz de se concentrar em outras tarefas e não presta atenção em sala de aula, pode-se considerar que o fator "motivação" pode estar implicado neste processo considerado como déficit de atenção. $\mathrm{O}$ segundo vetor, o de conduta, apresenta uma natureza diferente e parte do contexto relacional. As manifestações em relação às outras pessoas são consideradas como: desafio, oposição, confronto, insultos, agressões verbais ou físicas. Neste contexto, uma das características mais preocupantes do comportamento violento realizado por crianças e/ou adolescentes é a banalização, ou seja, o ato violento não é considerado como um ato sério. Na questão diagnóstica, salientou-se que a desatenção, hiperatividade e impulsividade não são sintomas específicos para o TDAH, mas podem fazer parte de um outro transtorno mental. Consequentemente, é necessário um diagnóstico diferencial cuidadoso e medidas terapêuticas adequadas.

Quando patologias psiquiátricas são confundidas com perturbações típicas da vida, percalços temporários, passa a ocorrer o que Frances ${ }^{10}$ denomina de inflação diagnóstica. Em muitas situações, o que tratamos não são doenças, mas transtornos da vida, percalços que pensamos ou somos induzidos a pensar que não daremos conta de lidar na contemporaneidade. Conforme o autor ${ }^{10}$, o modo mais adequado de lidar com os problemas da vida cotidiana é solucioná-los diretamente ou aguardar que desapareçam, buscar apoio da família, amigos, fazer mudanças necessárias na vida, enfim, buscar alternativas que fortaleçam o sujeito, no lugar de recorrer imediatamente a medicamentos. Para aqueles que sofrem de um transtorno mental real, a medicação pode ser necessária para restabelecer a homeostase, mas para aqueles que sofrem por problemas cotidianos, $o$ medicamento interfere na homeostase ${ }^{10}$.

Diante deste contexto, a principal preocupação que rege esta pesquisa é com as crianças e os adolescentes que estão sendo rotulados com diagnósticos falso-positivos de transtornos mentais e "tratadas" com intervenções medicamentosas como se tivessem transtornos mentais graves. Esta disseminação de diagnósticos de transtornos mentais em grande escala produz uma demanda de crianças e adolescentes que "necessitam de tratamento", o que pode favorecer o mercado dos profissionais da saúde, bem como a venda de medicamentos. Segundo Frances ${ }^{3}$, milhões de pessoas saudáveis estão sendo prejudicadas com diagnósticos psiquiátricos equivocados e tratamentos desnecessários, ao passo que os que possuem transtornos mentais graves não têm acesso às terapias necessárias.

Vale ressaltar a existência de crianças que apresentam um transtorno mental severo e que necessitam muito mais do que medicamentos para amenizar seu sofrimento e o de suas famílias. É importante esclarecer que não se pretende de forma alguma questionar a existência de transtornos mentais em crianças e adolescentes e da necessidade de acompanhamento em relação à saúde mental. O que está em discussão é o crescente número de diagnósticos falso-positivos de transtornos mentais em crianças e adolescentes e o alto consumo de medicamentos.

Diante deste cenário, esta pesquisa teve como objetivo compreender como os conteúdos veiculados nas redes sociais (comunidades virtuais) influenciam no modo pelo qual os familiares, membros destas comunidades, entendem o TDAH e o tratamento, bem como lidam com seus filhos com suspeita ou já diagnosticados com tal transtorno.

\section{Metodologia}

A pesquisa foi desenvolvida na perspectiva da Antropologia Médica ${ }^{11}$. A etnografia virtual ${ }^{12}$ foi elegida como metodologia de investigação para adentrar a uma comunidade virtual da rede social Facebook.

As redes sociais no âmbito virtual são ambientes em que as pessoas se reúnem publicamente por meio da mediação da tecnologia, onde ocorre a interação e troca social, bem como se configura em um espaço em que as informações são disseminadas, amplificadas reverberadas, discutidas e repassadas. Vale salientar que a expressão "rede social" refere-se ao relacionamento de pessoas no âmbito de um grupo socialmente organizado, que se comunicam por algum interesse comum ${ }^{13}$.

Hine $^{12}$ afirma que o agente de transformação não é a tecnologia em si, mas o uso e a construção dos sentidos em torno dela, fato que leva ao desenvolvimento de pesquisas sobre o cotidiano das pessoas no âmbito virtual. A etnografia 
configura-se como uma metodologia pertinente para se realizar esses estudos, uma vez que é possível explorar as relações existentes em diferentes contextos que se configuram no campo virtual. Os usuários das redes sociais vão construindo o sentido de suas práticas por meio de uma compreensão compartilhada, pelas diversas ferramentas que este espaço oferece, constituindo assim formas de ação social. A autora ${ }^{12}$ ressalta que há muito mais investimento em descobrir um futuro revolucionário da Internet do que investigar, minunciosamente, como está sendo utilizada e de que modo as pessoas incorporam o ambiente virtual em seu cotidiano.

$\mathrm{Na}$ ótica de Escobar ${ }^{14}$, este é um campo para a prática antropológica, sendo o estudo da cibercultura relacionado diretamente com as construções e reconstruções culturais em que as novas tecnologias estão embasadas, contribuindo ao mesmo tempo para essas formações. Em tal direção, a crença nas redes sociais representa uma invenção cultural que contribui para construir um novo mundo.

De modo geral, o mundo virtual propiciou uma transformação no contexto da pesquisa, de modo que os etnógrafos podem se libertar do "lugar" por meio da internet"15. As comunidades virtuais não são caracterizadas pela proximidade geográfica e nem pela herança em comum, mas são demarcadas pela comunicação por meio do computador e das interações on line. Atualmente, é possível observar uma sala de bate-papo virtual quase do mesmo modo que os acontecimentos em um lugar tradicional, o que possibilita fazer uma etnografia on line. A vida on line tornou-se bastante usual na contemporaneidade, assim o campo virtual pode ser seguramente incorporado como lócus de pesquisa pela etnografia ${ }^{15}$.

O termo "comunidade virtual" foi definido por Rheingold ${ }^{16}$, em 1993, como agregações sociais que surgem da rede mediante a uma quantidade suficiente de pessoas que se envolvem em discurssões públicas durante um tempo longo, formando teias de relações pessoais no ciberespaço. Casadó i Marín ${ }^{17}$ defende que comunidades virtuais sejam concebidas como redes de laços interpessoais que proporcionam sociabilidade, apoio, informações, identidade social, etc. Para a autora $^{17}$, uma comunidade virtual deve ser compreendida como um espaço de interação, onde resulta, impreterivelmente, o conhecimento das regras do jogo, conforme a concepção de campo bourdiana, em que o campo é um espaço de ação e de influência em que convergem relações sociais determinadas. Bourdieu ${ }^{18}$ afirma que os campos são os lugares de relações de forças que envolvem tendências próprias e probabilidades objetivas.

Para eleger, especificamente, a comunidade virtual de familiares de crianças e adolescentes com TDAH foi realizada uma seleção entre as comunidades virtuais. Primeiramente, realizou-se um levantamento exploratório no Facebook utilizando a sigla "TDAH" como palavra-chave. Posteriormente, fez-se uma análise das comunidades buscando-se encontrar aquelas constituídas principalmente por familiares que apresentassem diálogo entre os participantes sobre as crianças com TDAH e que fossem públicas. A comunidade selecionada extrapolou os conteúdos necessários para a pesquisa, sendo, portanto, suficientes para chegar aos resultados. As demais comunidades públicas foram descartadas por apresentarem essencialmente conteúdos de propaganda, ausência de diálogo entre os participantes e poucas postagens.

A escolha por uma comunidade virtual pública ocorreu devido ao fato de ela poder ser acessada por observadores invisíveis, além dos membros participantes deste ciberespaço, o que amplia de modo imensurável os acessos aos seus conteúdos. Segundo Angrosino ${ }^{15}$, o pesquisador pode atuar como observador invisível, sem ser visto, nem percebido pelos participantes. Desse modo, optou-se por permanecer como observadora invisível, pois não era objetivo da pesquisa intervir, mas sim compreender como os conteúdos veiculados nestas comunidades virtuais influenciam seus participantes no que diz respeito ao TDAH e o tratamento de seus filhos. A pesquisa no campo virtual ocorreu no período de maio de 2015 a setembro de 2016 .

As narrativas selecionadas foram de diálogos entre mães que manifestaram sua experiência com seus filhos em relação ao TDAH e interagiam com outras participantes da comunidade virtual. Este espaço era composto, predominantemente, por mães, por isso foram o público alvo da pesquisa. A análise das narrativas ocorreu na medida em que se observava as contradições, os consensos e a relevância das informações presentes nos diálogos das participantes, articulando com a literatura. No texto buscou-se apresentar recortes das narrativas na íntegra, conforme consta na rede social, preservando o anonimato das mães da comunidade, que foram representadas por letras maiúsculas referentes à identificação virtual. Adentra-se a seguir nesta comunidade virtual, cujo nome mencionado é fictício, com intuito de preservar o sigilo. 


\section{Resultados e discussão}

\section{Comunidade virtual de mães de crianças e adolescentes com TDAH}

Nesta comunidade as pessoas dialogam, contam suas angústias e compartilham com as demais os desafios e as vitórias de cada conquista com seus filhos. Segundo Terra ${ }^{19}$, pode-se dizer que as comunidades virtuais funcionam como as pequenas comunidades, onde todos se conhecem, sabem em quem podem confiar, a pessoa que é importante e quem decide quem é importante. As relações entre os atores sociais acontecem por meio das conexões e redes formadas entre os membros das redes sociais on-line.

Essa comunidade virtual tem um objetivo bastante específico, estabelecido pela organizadora e mediadora do grupo: Nosso grupo foi criado para interagirmos sobre o TDAH. Quase todas têm filhos ou parentes com esse transtorno e aqui tentamos nos ajudar, dividimos as angústias (LES). A narrativa da mediadora apresenta uma preocupação ao afirmar que quase todos têm um familiar com TDAH, pois a vulnerabilidade dos critérios diagnósticos do TDAH faz com que sintomas leves e transitórios (desatenção, impulsividade e hiperatividade) possam induzir as pessoas a pensarem que em quase toda família há um membro com a patologia.

O depoimento dessa mãe [...] tenho muito a aprender e entender melhor como lidar com o TDAH (PO), é um exemplo do que nos alerta Hacking $^{20}$ : uma vez consolidado o diagnóstico, a pessoa será tratada pelos demais de acordo com o seu transtorno mental.

A medicação é também causadora de angústia aos pais, não somente o TDAH, conforme relata uma mãe se referindo ao filho que toma medicação: Espero encontrar aqui um espaço para [...] dividir minhas angústias e aceitar melhor a medicação (VM).

Mesmo ciente dos males causados pela medicação, o tratamento medicamentoso tornase inevitável mediante os riscos apresentados à criança que não é tratada. Entre os riscos citados no DSM-54 estão: prejuízo no rendimento escolar e acadêmico, rejeição social, transtorno da conduta (adolescência), transtorno da personalidade antissocial (adulto) e transtornos por uso de substâncias.

\section{A Ritalina e o "sucesso" escolar}

O uso da Ritalina por crianças e adolescentes, como forma de tratamento para o TDAH para se adequarem às exigências das escolas, é bastante frequente em diversos países, sendo os Estados Unidos o principal consumidor. Mas esta prática extrapola os limites estadunidenses. Em 2012, o consumo de Ritalina em países fora dos Estados Unidos já representava 34\% do uso mundial ${ }^{2}$.

A adesão ao tratamento medicamentoso por parte das mães das crianças é reforçado por outras mães na comunidade virtual: Parabéns por ter aceitado a terapia medicamentosa. Ainda existe muito preconceito em relação a ela e é muito sofrimento para a criança ou adolescente com TDAH conseguir sucesso na aprendizagem sem ela (JGL). A exaltação aos medicamentos não se restringe apenas a este grupo de mães. Dantas et al. ${ }^{21}$ realizaram uma pesquisa no Facebook sobre os discursos que tratavam sobre crianças, TDAH e Ritalina. Observaram que os discursos são fortemente influenciados pelo poder biomédico, e a Ritalina é considerada como a "salvação" para as adversidades da vida, um alívio dos sofrimentos existenciais.

Nesta pesquisa, nos deparamos com esta mesma realidade: mães encontram na medicação para seus filhos um alívio para o sofrimento daquela família. Mediante os resultados imediatos da Ritalina, ficam esquecidas as suas reações adversas e o comprometimento futuro que esta droga pode causar às crianças. Afinal, o "sucesso" escolar é o que garante o futuro daquela geração e esta é a promessa deste medicamento. Prova disso é a indicação de usar apenas durante o período escolar, ou seja, tempo em que a droga produz o efeito desejado pelos professores e pais.

A persuasão de médicos e outros profissionais da saúde e da educação, que por sua vez foram influenciados de algum modo pelas indústrias farmacêuticas, faz com que os pais acreditem cegamente que seus filhos necessitam de uma "química" para o funcionamento do cérebro, conforme a narrativa dessa mãe: Temos que entender que o cérebro dessas crianças precisam dessa química para funcionarem de forma adequada (JGL).

As narrativas reporta-nos ao que Benevides ${ }^{22}$ considera como "indústria de normalização pela infância”, a qual se constitui pelo atrelamento entre o eixo "cultura do consumo - cultura do empreendedorismo" com o eixo "disciplinas-biopolíticas”. A indústria de normalização da infância inicia infiltrando a crença nos pais de que eles 
não sabem cuidar de seus filhos, promovendo um estado de incerteza, de anomia, de instabilidade e de liquidez dos valores, das crenças e das funções hierárquicas no contexto familiar ${ }^{22}$. Desta forma, as funções dos pais estão atravessadas pelas formas de saber dos especialistas das áreas médico-pedagógico-psi, bem como da invasão das logomarcas, das megaempresas e das tecnologias digitais como valiosos suportes para pais e filhos ${ }^{22}$.

Os méritos que deveriam ser atribuídos aos filhos, nas narrativas das integrantes da comunidade, parecem frutos do resultado de uma fórmula que leva ao sucesso, conforme incentiva essa mãe [...] lutem por seus filhos, não desistam de procurar o médico certo, o medicamento correto e tenham fé em Deus (MTM). Estamos diante de um sistema que corrompe os profissionais, que corrói o sujeito, despotencializa a infância e medica as populações. Cenário ilustrativo do que nos disse Foucault sobre a biopolítica e que, nas palavras de Benevides ${ }^{22}$, significa a codificação de um agrupamento de problemas e/ou acontecimentos referentes à vida e a espécie humana a partir de uma racionalidade governamental que possui como alvo a população, como instrumento os dispositivos de segurança e como finalidade a otimização da vida.

Vale ressaltar como a medicina, nessa comunidade virtual, é elevada ao status do divino, conforme se repete nas narrativas da mediadora do grupo, [...] medicina é coisa de Deus (LES). Na conversação anterior ela também relata: Deus cura através dos remédios (LES). Crença que atribui um poder à medicina, muito além de qualquer outra possibilidade de intervenção. A fusão entre valores culturais predominantes como a ciência (aqui representada pela medicina) e a religião fortalecem este entrelaçado jogo de poder.

Szasz $^{23}$ lembra-nos que o indivíduo na Idade Média tinha como objetivo a salvação. A santidade e a salvação formavam parte do jogo cristão, enquanto a bruxaria e a danação constituíam a outra parte, sendo que ambas pertenciam a um mesmo sistema de regras e crenças. Assim, sanções positivas ou negativas, recompensas ou punições, constituem pares complementares e compartilham do mesmo modo a forma e conteúdo do jogo. O jogo é composto por suas regras, caso alguma destas regras sejam modificadas, o jogo também sofrerá alteração. Se a preservação do jogo é desejada, ou seja, a manutenção do status quo social (religioso), o melhor a fazer é jogar o jogo do modo como é. Neste sentido, Szasz ${ }^{23}$ conclui que procurar e encontrar bruxas constituía uma manobra significa- tiva no jogo religioso da vida, do mesmo modo que procurar e encontrar a doença mental constitui uma estratégia importante do jogo médicoterapêutico contemporâneo.

\section{Reações adversas da Ritalina}

Diversas mães queixaram-se que seus filhos sofrem as reações adversas da Ritalina e, mesmo assim, os demais membros desta comunidade virtual apoiam para que insistam com o uso do medicamento. Pois esta é considerada a única alternativa para as crianças não se sentirem inferiores, como destacou uma mãe sobre seu filho: [...] prefere ser magro do que se sentir burro (LC), considerando que a perda do apetite é uma das reações adversas da Ritalina. A narrativa dessa mãe contempla a percepção sobre as crianças que não tomam medicação [...] eles se sentem deslocados e que são de outro mundo (LES). A recomendação de outra mãe sobre o uso da Ritalina é: Não tire, pois a qualidade de vida deles melhora muito (SL). Em relação as reações adversas, segundo essa mãe é melhor nem saber: Não fique lendo bula de remédio, faz a gente surtar (LES). Vale ressaltar que a bula da Ritalina é extensa (sete páginas) e descreve todas as reações adversas que as pessoas podem sofrer ao fazer uso deste medicamento, mas parece que isto só causa mais sofrimento às mães ao se confrontarem com esta realidade.

Os fatores de risco são um forte argumento para que as crianças continuem tomando a medicação. É praticamente uma ameaça às mães, conforme relata uma delas: Faça o tratamento, é melhor vc se arrepender de ter tentado, do que pagar o preço pra ver o resultado na adolescência (CPJ). Este "preço" está descrito no DSM-5 ${ }^{4}$ como as "Consequências Funcionais" de crianças com TDAH, as quais apresentam maior probabilidade do que as demais para desenvolver transtorno da conduta na adolescência e transtorno da personalidade antissocial quando adulto, aumentando a probabilidade de transtornos por uso de substâncias e prisão. Mediante estas consequências, fica difícil os pais deixarem de fazer o tratamento recomendado pelos médicos.

A postagem dessa mãe realmente impressiona: minha filha tem TDAH e transtorno de humor, ela toma Ritalina, 4 comprimidos de $10 \mathrm{mg}$, toma Risperidona e toma Lítio, mas continua muito ansiosa, não consegue aprender nada na escola, ela tem 10 anos (CPJ). Talvez a questão pertinente para este caso seja saber como uma menina de 10 anos pode aprender algo na escola nesta situação? A mãe queixa-se do comportamento da filha: ela 
fica nervosa, a gente briga, ela me responde e às vezes avança em mim (CPJ). Será que alguma vez foi questionado o efeito dos medicamentos nesta criança? Não houve comentários sobre esta postagem, nem sobre a "qualidade de vida" que os medicamentos proporcionam para as crianças, nem sobre os médicos "especialistas", muito menos sobre a "influência" de Deus.

O descaso com as reações adversas em decorrência do uso desta medicação aparece na investigação citada por Lima e Santos ${ }^{24}$, uma pesquisa realizada em 2013, pelo Núcleo de Farmacovigilância Sanitária da Secretaria de Estado da Saúde de São Paulo, a qual constatou que o metilfenidato (princípio ativo da Ritalina) é a primeira opção para o tratamento do TDAH. Entre os anos de 2009 e 2011, o aumento do consumo destes medicamentos foi de $164 \%$, tendo redução no período das férias e aumento no segundo semestre do ano letivo. Esta pesquisa também revela, com dados significativos, que estes medicamentos causam reações adversas como taquicardia, hipertensão, depressão, psicose, dependência e contrações musculares involuntárias. Estas informações, na maioria das vezes, sequer são passadas pelos médicos aos responsáveis pela criança. Estes, quando informados, geralmente não questionam a prescrição do medicamento, devido à confiança no profissional médico. Além disso, a maioria dos médicos não faz a reavaliação anual da terapêutica do uso dos medicamentos para verificar a necessidade de seguir ou não com o tratamento medicamentoso ${ }^{24}$.

\section{Dificuldades em lidar com os filhos sem medicação}

As narrativas das mães revelam que elas não sabem como agir com seus filhos e, mesmo recorrendo ao auxílio de profissionais, parece insuficiente, conforme relata sobre sua filha: Ela já passou por duas neurologistas, uma psicóloga, uma psicopedagoga e faz aula de reforço três vezes por semana. Mesmo assim, ainda não conseguimos uma melhora (ICV). Parece que a medicação se tornou uma necessidade para a convivência harmônica da criança na família e na escola, pois como se pode averiguar nas narrativas, as mães que decidiram pelo uso da medicação para os filhos avaliam positivamente a experiência: $A$ medicação foi um divisor de águas na vida do meu filho (JGL). Neste sentido, a pesquisa de Brzozowski e Caponi ${ }^{25}$ demonstrou que o diagnóstico de TDAH pode causar um alívio aos pais que não se sentem culpados pela dificuldade de aprendi- zagem e problemas de comportamento do filho. Entretanto, o diagnóstico de transtorno mental em uma criança pode gerar como consequência a incapacidade de desenvolver algumas atividades enquanto uma pessoa autônoma, semelhante àquelas que convivem no seu contexto, mesmo na idade adulta, por se reconhecer com os sintomas da doença.

O imperativo "que se deve fazer" e "como se deve fazer", conforme mencionam Dantas et al. ${ }^{21}$, vai desde o castigo à medicamentalização da criança, perpassada pelos saberes médico, psicológico e pedagógico. São formas de governar a infância, neste caso, por artifícios virtuais em que se constrói comunidades de pessoas adeptas a uma cultura que privilegia um mercado, bem como o controle desta população. Estas comunidades vão se constituindo e se multiplicando, movidas por um tipo de poder que intervém por meio de estratégias biopolíticas, as quais se expandem pelas redes sociais.

\section{Considerações Finais}

A comunidade virtual constituída por mães de crianças e adolescentes diagnosticados com TDAH discute principalmente o uso da medicação (Ritalina ou Concerta) para tratamento do TDAH em seus filhos. Causa muita angústia em algumas mães darem a seus filhos um medicamento controlado, ou seja, que pode causar dependência física ou psíquica. Observa-se que este grupo interage como apoio aos pais para superarem dita angústia e aceitarem a medicação.

As mães parecem acreditar que somente com o uso da medicação seus filhos conseguirão ter êxito na escola, apesar de passarem por inúmeros profissionais da educação e da psicologia. É inevitável a passagem pelo médico e a prescrição medicamentosa. Os depoimentos de mães que enaltecem o sucesso escolar dos filhos, "graças à medicação", é um modo de encorajar as demais participantes a seguirem o mesmo caminho.

A crença que a medicina e os medicamentos são meios de intervenção divina parece influenciar para que haja mais adeptos a este modo de enfrentar as dificuldades com os filhos. A palavra "Deus" aparece frequentemente nos discursos, o que nos leva a compreender que muitas mães acreditam que talvez a ajuda divina por meio de medicamentos contribua para a mudança no comportamento do filho.

$O$ fato é que a Ritalina causa reações adversas, fazendo com que as crianças passem a sofrer 
em função disso. O mesmo ocorre com a família, para quem o medicamento também gera um sofrimento. Os membros da comunidade compartilham desse sofrimento e apoiam os demais com a justificativa de que seus filhos também passaram por esta fase, mas que compensa continuar o uso do medicamento. Observou-se que algumas crianças apresentam um estado crítico de saúde pelas reações adversas dos medicamentos e o depoimento das mães é um verdadeiro pedido de socorro. Considera-se que há um grande descaso com relação às consequências que estes medica- mentos podem causar às crianças, tanto por parte dos familiares como dos profissionais.

A dificuldade dos pais de lidarem com seus filhos é um fato que impressiona, parece que a infância não cabe mais na contemporaneidade. Os pais recorrem aos diversos profissionais e técnicas para dar conta de uma função que, até pouco tempo atrás, era exercida naturalmente nas famílias. $\mathrm{O}$ sofrimento mediante esta dificuldade é provavelmente o que induz a pensar que há necessidade de uma solução médica, pois vivemos em uma era em que os percalços da vida tornaram-se patologias.

\section{Agradecimentos}

À Fundação de Amparo à Pesquisa e Inovação do Estado de Santa Catarina (FAPESC) e à Coordenação de Aperfeiçoamento de Pessoal de Nível Superior (CAPES) pelas bolsas de doutorado no Brasil e no exterior que possibilitaram a realização da pesquisa. 


\section{Referências}

1. Martínez-Hernáez A. "O segredo está no interior”. A neuropolítica e a emergência das neuronarrativas no consumo de antidepressivos. In: Caponi S, Vásquez MF, Verdi M, Organizadoras. Vigiar e medicar: estratégias de medicalização da infância. LiberArs: São Paulo; 2016. p. 61-70.

2. Whitaker R. Anatomía de una epidemia: medicamentos psiquiátricos y el asombroso aumento de las enfermedades mentales. Madrid: Capitán Swing; 2011.

3. Frances A. Voltando ao normal. Rio de Janeiro: Versal Editores; 2016.

4. American Psychiatric Association (APA). Diagnostic and Statistical Manual of Mental Disorders. $5^{\text {th }}$ ed. Arlington: APA; 2013.

5. Breggin PR. Talking back to Ritalin: what doctors aren't telling you about stimulants for children. Cambridge: Da Capo Press; 2001.

6. Whitaker R. Transformando crianças em pacientes psiquiátricos: fazendo mais mal do que bem. In: Caponi S, Vásquez MF, Verdi M, Organizadoras. Vigiar e medicar: estratégias de medicalização da infância. São Paulo: LiberArs; 2016. p. 13-28.

7. Conrad P, Schneider JW. Deviance and medicalization: from badness to sickness. Philapelphia: Temple University Press; 1992.

8. Luengo FC. A vigilância punitiva: a postura dos educadores no processo de patologização e medicalização da infância. Cultura Acadêmica: São Paulo; 2010.

9. Moya i Ollé J, Anguera Argilaga MT. Els problemes del comportament en els infants $i$ adolescents de catalunya. Trastorn per dèficit d'atenció/ trastorn de conducta. Necessitats educatives que generen. Educació Inclusiva. Síntesi de I'estudi lliurat al Parlament de Catalunya el 30 de març de 2010.

10. Frances A. Fundamentos do diagnóstico psiquiátrico: respondendo as mudanças dos DSM-5. Porto Alegre: Artmed; 2015.

11. Martínez-Hernáez A. Antropología médica: teorías sobre la cultura, el poder y la enfermedad. Rubí: Anthopos Editorial; 2008.

12. Hine C. Etnografía virtual. Barcelona: Editorial UOC; 2004.

13. Colnago CK. Mídias e redes sociais digitais: conceitos e práticas. In: Bueno WC, organizador. Estratégias de comunicação nas mídias sociais. Barueri: Manole; 2015. p. 3-22.

14. Escobar A. "Bienvenidos a Cyberia. Notas para una antropología de la cibercultura”. Rev. Estud. Soc. 2009; 22:15-35.

15. Angrosino M. Etnografia e observação participante. Porto Alegre: Artmed; 2009.

16. Rheingold H. La comunidad virtual: una sociedad sin fronteras. Barcelona: Gedisa; 1996.

17. Casadó i Marín LC. Trabajo de campo en comunidades virtuales pro self-harm. In: Romaní O, organizador. Etnografía, técnicas cualitativas e investigación en salud: un debate abierto. Tarragona: Publicacions URV; 2013. p. 113-141.
18. Bourdieu P. Os usos sociais da ciência: por uma sociologia clínica do campo científico. São Paulo: UNESP; 2004.

19. Terra CF. Mídias Sociais...e agora? O que você precisa saber para implementar um projeto de mídias sociais. São Caetano do Sul, Rio de Janeiro: Difusão Editora, Editora Senac Rio; 2011.

20. Hacking I. Múltipla personalidade e as ciências da memória. Rio de Janeiro: José Olympio; 2000.

21. Dantas JB, Dutra AB, Távora APG, Magalhães AMR, Silva CF, Fernandes JA, Lins SS. Devotos da Santa Ritalina: uma discussão sobre a infância medicalizada no contexto do Facebook. In: Dantas JB, organizador. A infância medicalizada: discursos, práticas e saberes para o enfretamento da medicalização da vida. Curitiba: CRV; 2015. p. 167-182.

22. Benevides PS. Governar através das crianças: notas sobre a indústria de normalização pela infância. In: Dantas JB, organizador. A infância medicalizada: discursos, práticas e saberes para o enfretamento da medicalização da vida. Curitiba: CRV; 2015. p. 35-48.

23. Szasz TS. O mito da doenca mental: fundamentos de uma teoria da conduta pessoal. São Paulo: Círculo do Livro; 1974.

24. Lima AF, Santos BO. Diagnóstico psiquiátrico como prática de reconhecimento perverso. In: Dantas JB, organizador. A infância medicalizada: discursos, práticas e saberes para o enfretamento da medicalização da vida. Curitiba: CRV; 2015. p. 13-34.

25. Brzozowski FS, Caponi S. Transtorno de Déficit de Atenção com Hiperatividade: classificação e classificados. Physis 2009; 19(4):1165-1187.

Artigo apresentado em 29/01/2018

Aprovado em 06/03/2018

Versão final apresentada em 11/06/2018 